\title{
Socio-Ecological Education of Students
}

\author{
${ }^{1}$ Vera S. Shilova, ${ }^{2}$ Natali L. Shechovskay, ${ }^{3}$ Ilya F. Isaev, ${ }^{4}$ Victoria B. Tarabaeva, ${ }^{5}$ Svetlana I. Tarasova \\ 1,2, 3, 4, 5 Belgorod State University 85, Pobedy St., Belgorod, 308015, Russia \\ *Email:shilova@bsu.edu.ru
}

Received: 21st October 2017 Accepted: 16th November 2017, Published: 31st December 2017

\begin{abstract}
In this article, we consider the results of theoretical and practical analysis of the problem of means in the system of higher professional education. These results acted as a starting point for studying the phenomenon of means in the context of the socioecological education of student youth. As a result, we identified the following general groups of educational tools: natural objects and their reproductive means, images and displays of phenomena, objects and processes of the surrounding socio-ecological environment, technical means, textbooks and study guides.
\end{abstract}

Keywords: Social and Ecological Education of Students, Means of Education, Means in the System of Social and Ecological Education of Students.

\section{Introduction}

One of the most important features of the development of modern society is the further exacerbation of social and environmental contradictions. The necessity of their resolution is conditioned by the need to preserve the favorable conditions of the environment of the mankind life, its health and the health of each person, the nature potential for sustainable social progress.

An important place in overcoming these contradictions is given to student youth. However, the effectiveness of solving emerging social and environmental problems is largely determined by the degree of its preparedness, already acquired experience of interaction with the natural environment, the ability to study, protect, renew and restore natural conditions and resources. Hence there is a need for a special - social and environmental education for student youth. It is closely intertwined with professional training, because each profession, in one way or another, is connected with the natural environment, uses its potential and, at the same time, has certain possibilities for preserving and renewing nature.

On the other hand, the social and environmental education of students is largely determined by a special system of means of its formation, which also enhance the effectiveness of the pedagogical process as a whole. It should be noted that the problem of means in the system of higher professional education has been never left without scientists' attention. Many foreign researchers have repeatedly applied to it both in the field of natural and humanitarian sciences: Markovich D. G.,1991; Meadows D., Randers J.,
Meadows D., 2008; Kofler W., 2012; Catton W.R., DanlapR.E., 1978; Paul Ecre., 1981; Trommer G., 1993;Bohac J., Kohout P., Janova Z., 2012;Wakai I., 2012 et al.

Let us add that the open classes in nature, special project days and weeks, the development of environmental games based on the desire to awaken a holistic emotional perception of the natural environment are in priority in the environmental education, for example, in England, the Netherlands, Denmark, Sweden, Germany, the United States and Canada (Environmental Protection Agency of the United States, 2009). There are non-governmental organizations, for example, the Field Studies Council in the UK. It has a network of 17 field training centers located throughout the country. FSC conducts extra-curricular activities for children of adjacent schools in the form of 3-4-day field workshops, the organization of study and orientation tours, trips for children with parents, students and pensioners. Another example is the Creek Farm Education Associates in the United States, a non-governmental educational organization created to promote the principles and approaches of "naturalistic" education (Environmental Protection Agency of the UNITED STATES, 2009. - PP.1-13).

Among domestic scientists who laid the didactic basis of the system of higher education, it is necessary to name the works of Arkhangelsky S.I., 1978; Skatkin M.N., 1982; Talyzina N.F., 1984; Krivitsky B.Kh., 1986; Menyaev A.F., 1996; Popkov V.A. and Korzhueva A.V., 2001; Smirnov S.D., 2007; Slastenin V.A., 2007; et al.

As for the means for the proper environmental education of student youth, which is the basis of socio-ecological education, first of all, the studies of Mamedov N.M., 1996; Glazachev S.N., 1998; Sitarov V.A., Pustovoitov V.V., 2000; Mazur I.I., 2001; Shilova V.S., 2006; Glazacheva O.A., Gagarin A.V., 2011; Grishaeva Yu.M., KosonozhkinV.I., 2013, et al. should be noted.

\section{Materials and Methods}

The following theoretical approaches (systemstructural, differentiated, activity-oriented) and methods were used in the article preparation: analysis, synthesis, abstraction, generalization, and concretization.

The system-structural approach allows considering the subject of research from the position of linking its elements, hierarchy, and subordination of structural components. A differentiated approach helps 
distinguish the elements of the system by dividing the whole into parts and studying each of them separately. The activity approach is related to the organization of students' activities in the natural environment, the implementation of individual actions and operations aimed at its preservation, improvement, and renewal. These approaches allow us to determine the specific means of socioecological education for students. With regard to methods, the choice of analysis as one of the most important in the study is due to the fact that it is a method of obtaining new knowledge. The latter is precisely one of the main tasks of this study.

Let us recall that in the most general sense, analysis is a process of mental or factual decomposition of the whole into its constituent parts. This makes it possible to reveal the construction of the object under study, i.e. its structure. In turn, the dismemberment of a complex phenomenon, an object into simpler elements, makes it possible to separate the essential from the nonessential, to reduce the complex to the simple, to isolate the contradictions, various tendencies, and stages in it. The analysis plays a crucial role in the cognitive process and is carried out at all its stages (Philosophical Dictionary, 1991). On the other hand, which is also important for our research, in thinking operations, the analysis acts as one of the logical methods of thinking, is accomplished with the help of abstract concepts and is closely related to a number of other thought operations: synthesis, abstraction, generalization.

Synthesis is the very opposite process, consisting in the joining some parts into a whole. The scientists reasonably attribute analysis and synthesis to widespread methods of scientific thinking. These methods are interrelated, deeply rooted in the practical activities of man in the development and transformation of the surrounding world. The analysis and synthesis can turn to a special method of research of a particular science from the general method, for example: methods of mathematical, chemical or social analysis. Analysis is related to synthesis in any form. However, in practice, the analysis is associated with abstraction, generalization and other mental operations (Alekseev P.V., PaninA.V., 1991).

Dedicated methods of analysis, synthesis, abstraction, generalization and concretization make it possible to solve one of the main tasks of this study at the theoretical level - the need to obtain new knowledge, in particular - the essence of the concept definition of "means of socio-ecological education of students", as well as the allocation of specific means.

\section{Results and Discussion}

Professional training in the system of modern higher education requires, as already noted, mandatory ecologization of not only its goals, content, but also other components of the pedagogical process: methods, means and forms of organization. It should be noted that the features of education in the higher school have long been studied by the scientists, and the various aspects of it have been revealed: historical, personal, activity, managerial, professional, creative (Skatkin M.N., 1982; Slastenin V.A., 1997; Smirnov S.D., 2007, et al.). The remark of S.I. Arkhangelsky is also fair. One time he noted the complex systemic nature of the educational process in the university, expressed by an infinite variety of states, behaviors, relationships, the connections of its constituent components. According to him, the main components of this process include: the content of education (through the relevant subjects and types of educational work); training methods; forms and means of training; educational and scientific work of students (the object of study); teaching activity of teachers (Arkhangelsky S.I., 1978).

The study of the problem of means in the system of social and environmental education of students required the establishment of their essence, classifications, and conditions of effectiveness. The basis for studying this problem was the work of domestic scientists and teachers and other authors. They laid the theoretical foundation for professional training in the system of higher education: they revealed their essence and developed various classifications (ArkhangelskyS.I., 1978, Slastenin V.A., 2007), described some of them (Smirnov S.D., 2007; Popkov V.A., KorzhuevA.V. , 2001); established optimal combinations (SkatkinM.N., 1982); determined the conditions for the effectiveness of using the means of teaching students and the prospects for their application in the pedagogical process of the university. Thus, the didactic means mean all kinds of means of pedagogical work (Skatkin M.N., Shakhmayev N.M., 1982); a material or ideal object that is "placed" between the teacher and the student and is used to assimilate knowledge, form the experience of cognitive and practical activity (Minyaev A.F., 1996). All researchers engaged in this problem agree that teaching means are an indispensable element of the pedagogical process, regardless of the conditions of its course. Teaching means are included in the classrooms, the educational and informative environment. They act as a carrier of educational information and a tool for the activities of the teacher and the student.

The accumulated theoretical and practical experience on the problem of the means of teaching the students of the university made it possible to determine the means in the system of ecological training of professional personnel. So, we considered the basic means of forming the teacher's ecological culture (Glazachev S.N., 1998; Sitarov V.A., Pustovoitov V.V., 2000); culture as a means of harmonizing relations between society and nature (Mazur I.I., Kozlova O.N., Glazachev S.N., 2001). Of the latest trends related to this problem, we should mention:creation as a means of special space - a space of design-eco-education (Glazacheva A.O., Gagarin A.V., Glazachev S.N., 2011), development of a humanitarian technology for designing an individual eco-professional educational space, 
including specific technological means (Glazachev S.N., Grishaeva Yu.M., Kosonozhkin V.I., 2013).

It should also be noted that the problems of educational tools in the field of social and environmental relations are also being actively considered by foreign researchers. In this regard, we should note the activities of the society "Gesellschaft Sozial- Ökologische Forschung (SÖF), 2015-2020", which develops the concept of socio-ecological research.In 1990, the National Law "On Education in the Environment" was adopted in the United States, within which a federal structure for the development of environmental education was established and the state support was provided for the initiatives in this area, including "green schools", field centers, teacher training, ecological movement, etc. In the XXI century, the environmental programs are included in the state standards of all levels of education in the USA. The analysis of environmental education programs reveals the following trend: from the initial sensory cognition of nature and upbringing of children's love for it - to committing actions that affect sustainable development (Environmental Protection Agency of the United States, 2009.).

Thus, there is an obvious interest in the problem of means of education, and in various branches of pedagogical science. The task of this study required the definition of the essence, structure and basic classifications of the means of socio-ecological education of students. As a result, it was established that the phenomenon of teaching means is studied not only at the general scientific level, but also at a specific scientific level. At the same time, the problem study involves not only revealing the essence of the means, but their functions, features, classifications. The research results are as follows.

Firstly, the general features of the means of education and their functions have made it possible to define the essence of the concept of "means of socioecological education for students of youth", which include individual natural and artificial objects, phenomena, processes or a set of adaptations used in the joint activity of the teacher and the students directed on the assimilation of all elements of socioecological experience: social-ecological knowledge, skills, creative and emotional value-attitude to nature; its use in the theoretical and practical activities (Shilova V.S., 2006, 2015). These means have the same functions as the means of education in general, however, the complex nature of socio-ecological knowledge and skills, other elements of the interaction experience between society and natural environment require the implementation and integrative function (Ibid.).

Secondly, they mean the development of the system of social and environmental education of students, the need to improve the pedagogical process in the university, the intensification and effectiveness of educational activities carried out with the help of technical training means (TTM) (Smirnov S.D., 2007; Krivitsky B.Kh., 1986; Talyzina N.F., 1984).
Thirdly, the computers and computer devices, other means of computer technology, to which all the researchers pay their attention, take a special place in the system of teaching means in higher education. At the same time, the problem of modern textbooks and teaching aids, which remains an important source of special knowledge and one of the main means of teaching, continues to be relevant (Popkov V.A., Korzhuev A.V. 2001).

Fourthly, all the above, as well as the integration principle, allowed us developing an approximate classification of social and ecological education for students. It includes the following groups (Shilova V.S., 2006, 2015):

\section{Natural Objects and Means of their Reproduction:}

- Objects of the Environment (anthropogenic forms of relief, samples of individual components of nature, cuts: soil, geological; natural water bodies used by man; natural plant communities used by man; natural animal organisms used by man; samples of natural resources; natural conditions used by man; archaeological excavations; archaeological finds; historical monuments; monuments of culture; monuments of nature; economic objects; results of economic activity; historical sources and documents);

- Instruments and Devices for the Experiment (measuring instruments, instruments for experiments with samples of nature components; a collection of natural objects; a collection of results of economic activities; a collection of archaeological finds, the reconstruction of historical and natural monuments, the reconstruction of natural monuments, etc.).

\section{Images and Displays of Phenomena, Objects and Processes of the Environment: \\ - Mock-ups and Models (dioramas of} examples of the interaction of society with nature, models of individual forms of relief, models of historical objects, models of existing production, models of plants and animals, models and mock-ups of monuments of nature and culture, etc.);

- Operating Models (models of operating natural processes, dynamic weather calendar, dynamic tables, transparencies, orographic models, etc.);

- Graphic Means (tables; maps; historical maps; schemes; diagrams; charts; cartoschemes; cartograms; cartodiagrams; plan charts; geographical and historical pictures; photographs; drawings; works of geographical and historical painting; punched cards; contour maps; meters).

\section{Technical Means:}

- Means of information provision: audio (microphone, tape recorder, player); visual (dia-, graphical projector); audiovisual (educational films, educational television, video disc systems);

- Technical Means of Management;

- Technical Means of Learning Management (computer equipment, computer networks). 


\section{Textbooks and Study Guides:}

- Textbooks and Study Guides for teachers and students (textbooks and study guides on social ecology, collections of questions and tasks on social ecology, books for reading on the problem of interaction between society and nature, study guides for practical works on social ecology, workbooks for students on social ecology; reference books on social and environmental problems, didactic and methodological manuals for the teacher, programs on social ecology courses, anthologies, etc.).

\section{Conclusions}

Summarizing, we note that the selection of means in the process of social and environmental education of students is carried out taking into account its specific conditions, the age characteristics of students, the educational and material base, the experience of the teacher's professional activities. The identified means are used both in the process of individual work with students, and in group, frontal and combined forms. The considered element of the process of socioecological education of students, in turn, is the content of a certain pedagogical technology that implements the functions and tasks of this process.

At the same time, the study has shown the need for further search for effective means of social and environmental education for students, the development of diagnostic and teaching technologies, creating conditions that optimize the interaction between the teacher and the students.

\section{References}

[1] Alekseev, P.V., Panin, A.V. 1991.The theory of knowledge and dialectics. - M. - 383p. (In Russian).

[2] Bohac J., Kohout P., Janova Z. Environmental consessonsessand education in Czech Republic //Proceeding of the international conference "Ecological Culture in the Global World: Russian Education Modernization in the International Strategy Context". /Herald of the International Academy of Science. Special issue. - 2012.-P.20-23

[3] Didactics of high school. Monograph.Ed. M.Skatkina - M., 1982. (In Russian).

[4] Environmental education. URL: http://en.wikipedia.org/wiki/ (access date: 03.02.2012).

[5] Environmental education highlights - examples of EPA's current efforts to solve our nation's environmental challenges through environmental education. - environmental protection agency UNITED STATES, 2009.- PP. 1-13.

[6] Federal State Educational Standard, December 22, 2009, (788), March 22, 2010, (200).(In Russian).
[7] GlazachevSN The monograph. Ecological Culture of the Teacher: Research and Development of the Eco-Humanitarian Paradigm. Monograph.-M., 1998.432 p.(In Russian).

[8] Glazachev S.N., Grishaeva Yu.M., Kosonozhkin V.I. Modernization of technologies of formation of ecological culture of students of a liberal arts college. - M., 2013.- 204 p. (In Russian).

[9] Glazacheva O.A., Gagarin A.V., Glazachev S.N. M., 2011.- 179 p. (In Russian).

[10] Kofler W. Now can we optimize communication about systemic aspects of our complex world? // Bohac J., Kohout P., Janova Z. Environmental consessonsess and education in Czech Republic. //Proceeding of the international conference "Ecological Culture in the Global World: Russian Education Modernization in the International Strategy Context"./Herald of the International Academy of Science. Special issue. - 2012.-P.53-57.

[11] Krivitsky B.Kh. Technical means of control and management of training. - M., 1986.(In Russian).

[12] Mamedov N. M. Culture. Ecology.Education, Moscow, 1996, 11 p. (In Russian).

[13] Mazur I.I., Kozlova O.N., Glazachev S.N. The path to ecological culture. - M., 2001.- 194 p. (In Russian).

[14] Markovich Danilo Giacomo. Social ecology. / Trans. From the Serbian-Croatian.- M., 1991.- 176 p.

[15] Menyaev A.F. Means of education. - M., 1996. (In Russian).

[16] Meadows D., Randers J., Meadows D., Limits to Growth / The 30-Year Update. - Chelsea Green Publishing Company White River Junction, Vermont, 2008

[17] Paul Ecre. Untersuchungenzumpädagogischen Können.-Berlin: Volkundwissen Wolkseigener Verlag, 1981. - 203 p.

[18] Popkov V.A., Korzhuev A.V. Didactics of the higher school. - M., 2001. (In Russian).

[19] Pedagogy of professional education. Ed. V.A. Slastenina. - M., 2007.-368 p. (In Russian).

[20] Catton W. R., Danlap R. E. Environmental sociology: A new paradigm // Amer. Sociologist. 1978.

[21] Sitarov VA, Pustovoitov V.V. Social ecology.M., 2000. - 280 p. (In Russian). 
[22] Smirnov S.D. Pedagogy and psychology of higher education: from activity to personality. - M., 2007. (In Russian).

[23] TalyzinaN.F. Management of the learning process. - M., 1984. (In Russian).

[24] Trommer G. Naturim Kopf: Die Geschichte ökologischbedeutsamerNaturvorstellungen deutschenBildungskonzepten. Weinheim, 1993.

[25] Shilova, V.S. 2006. Social-ecological education of students.Monograph. - Belgorod. - 247p. (In Russian)

[26] Shilova, V.S. 2015. The differentiation in the system of social and environmental education of students.Monograph. - Belgorod.-256p. (In Russian)

[27] Social ecological research-funding concept for research related to the company's sustainability in 2015-2020 GesellschaftSozial-ökologischeForschung (SÖF). The German Federal Ministry of education and research (BMBF).-38p.http://www.fona.de/de/publikationen.

[28] Wakai I. Current status and future outlook of ecological education at Osaka Sangyo University // Environmental consessonsess and education in Czech Republic. // Proceeding of the international conference "Ecological Culture in the Global World: Russian Education Modernization in the International Strategy Context". / Herald of the International Academy of Science. Special issue. - 2012. - P.105109. 